\title{
A INTERNACIONALIZAÇÃO DO MERCADO BRASILEIRO DE DERIVADOS LÁCTEOS - ANÁLISES SOBRE A ATUAÇÃO DE OLIGOPÓLIOS, OLIGOPSÔNIOS E TRADE COMPANY
}

Resumo: $O$ trabalho em questão apresenta uma análise sobre a influência criada pelas Trade Company no mercado nacional de leite e derivados lácteos, promovendo por meio da oferta, a regulação dos preços destes produtos no mercado e assim desdobrando flutuações nos preços praticados por toda a cadeia produtiva do leite - CPL. Ainda busca destacar que a variação dos preços internacionais ainda estabelece comportamento cíclico nos volumes de importação/exportação, criando condições ideais para que grandes empresas nacionais e multinacionais possam condicionar os preços praticados principalmente para elos frágeis do processo, neste caso o produtor rural, que tem a cotação de sua mercadoria mais relacionada por aspectos internacionais do mercado do que pela sazonalidade do volume de produção condicionados pelos elementos naturais ou estruturais regionais de cada região do Brasil.

Palavras-chave: Leite. Mercado. Importação. Exportação. Preço.

\section{THE INTERNATIONALIZATION OF THE BRAZILIAN DAIRY DERIVATIVES MARKET - ANALYSIS OF THE PERFORMANCE OF OLIGOPOLIES, OLIGOPSONS AND TRADE COMPANY}

Abstract: The work in question presents an analysis of the influence created by the Trade Company in the national market of milk and dairy products, promoting the regulation of the prices of these products in the market and thus deploying fluctuations in prices throughout the milk production chain - CPL. It also seeks to highlight that international price variation still establishes a cyclical behavior in import / export volumes, creating ideal conditions for large national and multinational companies to condition the prices practiced mainly for fragile links of the process, in this case the rural producer, who has the quotation of its merchandise more related by international aspects of the market than by the seasonality of the volume of production conditioned by the natural or structural elements of each region of Brazil.

Keywords: Milk. Market. Imports. Exports. Price.

\section{LA INTERNACIONALIZACIÓN DEL MERCADO BRASILEÑO DE DERIVADOS LÁCTEOS - ANÁLISIS SOBRE LA ACTUACIÓN DE OLIGOPOLIOS, OLIGOPONIOS Y TRADE COMPANY}

Resumen: El trabajo en cuestión presenta un análisis sobre la influencia creada por las Trade Company en el mercado nacional de leche y derivados lácteos, promoviendo por medio de la oferta la regulación de los precios de estos productos

\footnotetext{
1 Universidade Federal de Santa Catarina, Departamento de Geociências, Florianópolis, Brasil, pablocamilo1@hotmail.com, https://orcid.org/0000-0002-8679-1012
} 
en el mercado y así desdoblando fluctuaciones en los precios practicados por toda la cadena productiva de la leche - CPL. En este caso, el productor rural, que tiene que ver con los precios de las exportaciones, se ha convertido en una de las principales empresas del mercado, la cotización de su mercancía más relacionada por aspectos internacionales del mercado que por la estacionalidad del volumen de producción condicionados por los elementos naturales o estructurales regionales de cada región de Brasil.

Palabras clave: Leche. Mercado. Importación. Exportación. Precio.

\section{Introdução}

O entendimento acerca do processo de formulação de preços praticados na cadeia produtiva do leite, requer considerável conhecimento sobre as características dos diferentes agentes que compõem o complexo produtivo. Uma vez isso considerado é possível identificar quais mecanismos, mercadológicos, estratégicos e de imposição que são "postos a mesa" para que a o leite e seus derivados constituam uma ampla gama de relações comerciais entre os agentes do complexo produtivo por todo o Brasil e exterior.

Neste sentido um aspecto importante a ser considerado é o amplo processo de concentração pelo qual passou a indústria de laticínios e o setor de atacado e varejo. Tal processo se consolidou após a década de 1990 quando o cenário político estabeleceu um ambiente econômico e institucional favorável a abertura de mercado e consequentemente a entrada de capital e empresas multinacionais para atuarem neste setor. Foi por meio de um amplo processo de fusões e aquisições que a indústria de laticínios e o setor de atacado e varejo foi reconfigurado resultando em duas características principais - concentração e desnacionalização.

Processos de desnacionalização e concentração promovidos a partir da década de 1990 são ainda potencializados pela especulação financeira que estimula os proprietários de empresas a realizarem Initial Public Offering - IPO, ou seja, transformarem suas empresas em sociedades anônimas, ofertando ações desta no mercado e assim captando recursos que podem financiar novas fusões e aquisições, aumentando os ativos da empresa e consequentemente garantindo mais captação de recursos dos investidores.

Segundo a Internacional Farm Comparison Network -IFCN, (2014), no Brasil das 12 maiores empresas de lácteos atuantes, 5 são multinacionais processando aproximadamente $25 \%$ do leite captado no país (leite formal), 4 destas empresas estão estabelecidas entre as 12 maiores processadoras do mundo, responsáveis por 
captar cerca de $40 \%$ do leite mundialmente produzido. Estas empresas apresentaram os maiores percentuais de crescimento do segmento na última década. A líder, Dairy Partners Américas- DPA com 38\%, seguida pela Lactális com crescimento de $28 \%$, a Vigor (Lala) com $26,8 \%$ e a Danone com $23,6 \%{ }^{2}$.

Ainda relacionada a atual configuração da CPL, outra condição a se considerar é o caso da atuação da multinacional Tetra Pak, que segundo o relatório criado pela CPI do leite (2003) detêm quase $100 \%$ da produção de embalagens cartonadas para o leite UHT. Ainda segundo este relatório, naquele ano a embalagem para um litro de leite custava cerca de $\mathrm{R} \$ 0,19$ que somados as embalagens secundárias de armazenamento este valor ficaria em $\mathrm{R} \$ 0,25$ por litro.

No que tange o setor de atacado e varejo, segundo a Associação Brasileira de Supermercados - ABRAS (2014), as 500 maiores empresas de distribuição atacado e varejo obtiveram um faturamento de $R \$ 229,4$ bilhões. A quantidade de lojas administradas por este grupo cresceu $10,2 \%$, totalizando 7.803 operações. Isso representa um incremento de 721 unidades. As 50 maiores cresceram cerca de $10,75 \%$ e somam receitas no valor de $\mathrm{R} \$ 192,5$ bilhões, O líder em faturamento foi o Grupo Pão de Açúcar com aumento de 12,6\%, (R \$ 57,23 bilhões em 2012 para $\mathrm{R} \$$ 64,4 bilhões em 2013). O número de lojas da rede aumentou de 1.641 para 1.757 , somando 116 lojas novas.

Ao considerar os dados apresentadas, norteadas por uma metodologia empírico e analítica da realidade concreta é possível perceber que na CPL existe a atuação de empresas em nível de oligopólio e oligopsônio, sendo este aspecto indispensável para promover ações estratégicas no controle da oferta e preços no mercado nacional de leite e derivados lácteos. Para tanto, considerando que são empresas multinacionais a especulação se dá em nível mundial, fazendo com que as Trade Company, não sejam apenas empresas de compra e venda de mercadorias, mas atuem como mecanismos de regulação de preços nacionais por meio da venda ou aquisição destes produtos no mercado internacional, por meio de complexos sistemas de importação e exportação.

Um estudo realizado pelo sistema FAEP (2017) mostra que o estado do Paraná produz cerca de 4,7 bilhões de litros de leite por ano, seu consumo interno é de 1,9

\footnotetext{
${ }^{2}$ Das 12 maiores empresas de lácteos do Brasil, 7 não são multinacionais, sendo 5 cooperativas: a Itambé, em Minas Gerais, Centro Leite em Goiás, Frísia, Confepar e Frimesa no Paraná. A participação das cooperativas de leite no volume captado no país é de aproximadamente $10 \%$. Já as empresas de capital privado são apenas 2: a Laticínios Bela Vista (Piracanjuba) de Goiás e Jussara de São Paulo, sendo essas responsáveis por cerca de 7,5\% do total captado no país. (LEITE BRASIL, MILK POINT e EMBRAPA/Gado de Leite, 2014).
} 
bilhão de litros, seu superávit produtivo de 2,6 bilhões de litros é exportado para outros estados brasileiros e para outros países. Em 2014 chegou a exportar cerca de 6 mil toneladas de derivados lácteos, porém mesmo com um superávit significativo o estado importou cerca de 15 mil toneladas de derivados lácteos em 2016, "entre os principais destinos desses produtos figuram indústrias alimentícias variadas, bem como laticínios e redes atacadistas".

Isto posto, o texto em questão tem como principal objetivo esclarecer a dinâmica exercida pelas trade company tidas aqui como empresas processadoras de lácteos, atacados, varejos e comerciantes sem fábrica, onde considera-se que o primeiro grupo, por estar em uma posição estratégica dentro da CPL, possui maior capacidade de condicionar os preços praticados por todo o segmento, controlando o preço do leite pago ao produtor ou pelo leite cru refrigerado no mercado spot ${ }^{3}$.

\section{A influência das trade company e do mercado internacional de derivados lácteos na configuração dos preços na cadeia produtiva do leite no Brasil.}

A desnacionalização da indústria láctea do Brasil tem possibilitado que, cada vez mais, se estabeleça uma relação entre os preços praticados internacionalmente para as commodities lácteas e o comportamento dos preços no mercado doméstico. A composição dos preços da matéria-prima ligados aos fatores endógenos de cada lugar está dando espaço aos condicionantes mercadológicos em nível mundial. Neste sentido, percebe-se que tais influências estão sendo canalizadas pela consolidação dos mecanismos financeiros nas empresas de laticínios. Segundo Balaestro e Lourenço:

Em larga medida, a financeirização consiste em um processo de concentração de poder em torno do capital financeiro. A origem desse grande poder das finanças passa pelo progressivo deslocamento de um sistema de financiamento baseado em bancos para um sistema baseado em mercado de capitais. No elo da produção do agronegócio brasileiro, poderiam ser acrescidas as grandes empresas fornecedoras de insumo e as tradings company (BALESTRO e LOURENÇO, 2014, p. 246).

\footnotetext{
${ }^{3} \mathrm{O}$ significado que o termo spot tem é imediato, instantâneo. É um mercado de commodities (no caso da indústria de laticínios pode ser também de leite cru refrigerado) em que os negócios são realizados à vista e entrega imediata. Geralmente a comercialização se dá em um prazo, normalmente em poucos dias, e a remessa é única e por tempo limitado, servindo quase sempre para suprir uma demanda imprevista. O mercado spot, distingue-se do mercado futuro ou do mercado a termo, em que os contratos são feitos para pagamento e entrega posterior, geralmente variando de cinco dias a dois anos após a negociação. Há dois tipos básicos de mercado spot: o mercado primário ou local, situado junto às zonas produtoras e o mercado central, localizado nos pontos de distribuição. Para a indústria de laticínios o mercado spot e traduzido em compra e venda de leite fluido cru refrigerado, mediante os critérios acima destacados.
} 
Para tanto, observa-se o comportamento dos preços na maior Trade Company de comercialização de leite do mundo a Global Dairy Trade -GDT. Esta Trade organiza leilões quinzenais em nível mundial de produtos lácteos, onde 5 das maiores processadoras de leite do mundo ofertam suas mercadorias, interferindo sensivelmente nos preços de derivados mundiais e consequentemente nos preços pagos pela matéria-prima em países produtores ${ }^{4}$.

Conforme a homepage da GDT, o leilão do dia 18/05/2017 reuniu cerca de 553 licitantes em 19 rodadas de negociação, onde 103 destes licitantes fecharam negócio de 21.236 toneladas de commodities lácteas a um preço médio de U\$ 3.313 por tonelada. Isso representa um mercado que movimenta quinzenalmente cera de U\$ 70 milhões de dólares em produtos lácteos.

Uma empresa de laticínios de grande porte, instalada em países com mercados consumidores de lácteos consolidados, como o caso do Brasil, captará leite produzido regionalmente, mas também comprará derivados (commodities) para suprir suas demandas sempre que a oferta e os preços internacionais cotados pelo leilão GDT estiverem favoráveis. Diz-se aqui, então, que, uma vez podendo adquirir leite fluído de produtores nacionais e principais commodities derivadas do leite, esta empresa escolherá a fonte de captação de matérias primas que esteja com melhor preço ${ }^{5}$.

É conveniente salientar que muitas empresas processadoras de leite têm como principais clientes outras empresas alimentícias (chocolates, biscoitos, comidas préprontas etc.) que por sua vez, demandam basicamente derivados lácteos commodities que servirão de ingredientes para a produção de outros alimentos destinados ao consumidor. Conclui-se que, uma vez inseridas no mercado internacional de compra e venda de commodities lácteas por meio do leilão GDT, as

\footnotetext{
4 Segundo Rafael Ribeiro de Lima Filho em reportagem exibida no portal Scot Consultoria em 04/12/2013 as empresas que ofertam derivados lácteos através do leilão GDT são: Fonterra: (Localizada na Nova Zelândia, é considerada a maior processadora de leite do mundo), Dairy América:(empresa formada por representa quatro cooperativas localizadas nos Estados Unidos da América), Murray Goulburn (Localizada na Austrália, é responsável por processar um terço do leite produzido no país), Arla (localizada na Dinamarca, Suécia e Alemanha e mais de vinte países), Amul ( de origem indiana, onde conta com cerca de 3,2 milhões de produtores e capacidade de processar 20 milhões de litros por dia) Eurosérum (de origem francesa, atualmente e a maior produtora mundial de leite em pó desmineralizado).Neste leilão são comercializados gordura de leite anidra (gordura desidrata), manteiga, leite em pó de manteiga, cheddar, lactose, caseína, leite em pó desnatado, leite em pó integral.

${ }^{5}$ Para a industrialização e comercialização de leite UHT, esse caso não se aplica, pois, o leite nestas condições possui atualmente níveis de comercialização a nível mundial muito baixos. Assim grande parte do leite UHT comercializado nacionalmente é produzido de leite captado no Brasil. Fato este que justifica a manutenção de produtores de leite agregados as empresas de laticínios e reforça a ideia sobre o direcionamento do leite captado para diferentes linhas de produção de derivados lácteos como foi exposto no capítulo 02.
} 
empresas passaram a especular melhores preços com base nos preços praticados internacionalmente, assim, os preços nacionais do leite, por toda a cadeia produtiva, responderão sensivelmente às flutuações dos preços internacionais por meio de um processo simplificado de oferta e demanda 6 .

Os gráficos apresentados subsequentemente permitem observar 0 comportamento e a relação estabelecida entre os preços praticados internacionalmente no leilão GDT, os preços médios pagos aos produtores em alguns países e as importações e exportações de commodities lácteas no Brasil de janeiro de 2012 a março de 2017.

\section{GRÁFICO 01 - Preço médio commodities lácteas no leilão GDT - Valores em Dólar}

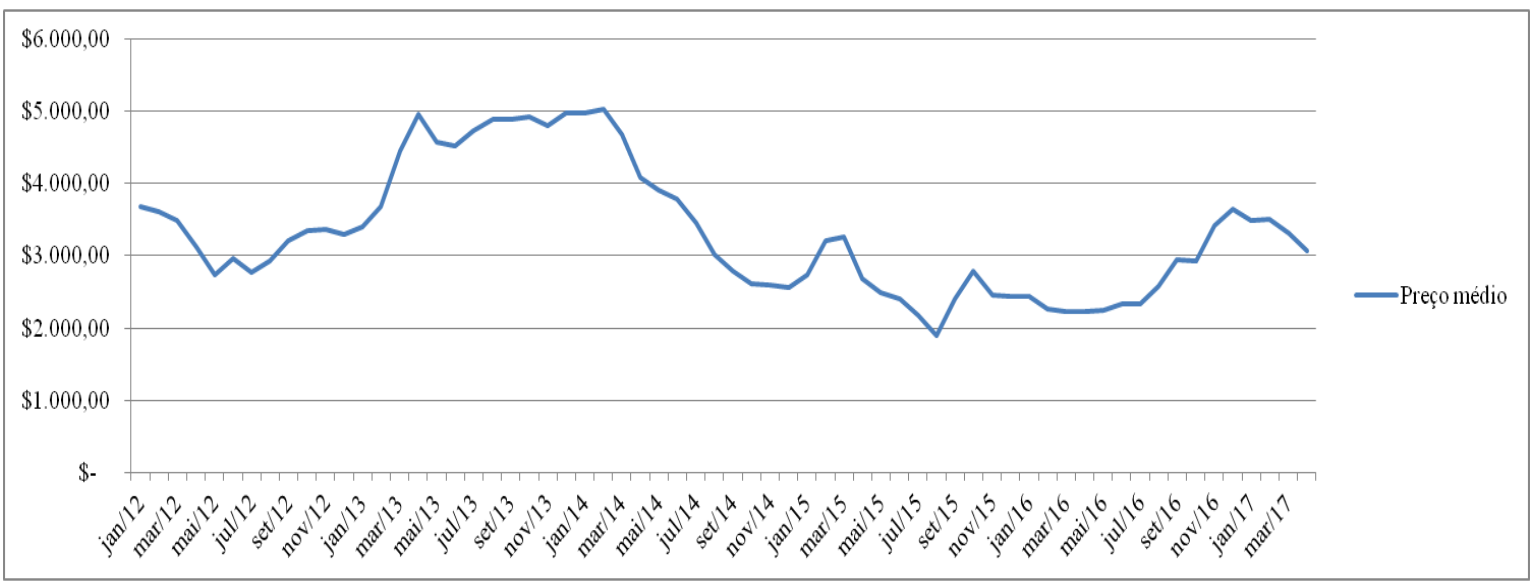

Fonte: Estatísticas do Leite Milk Point, Global Dairy Trade. Disponível em: www.milkpoint.com.br Acesso em 23/05/2016

\section{GRÁFICO 02 - Preços pagos ao produtor em diversos países - valores em Dólar.}




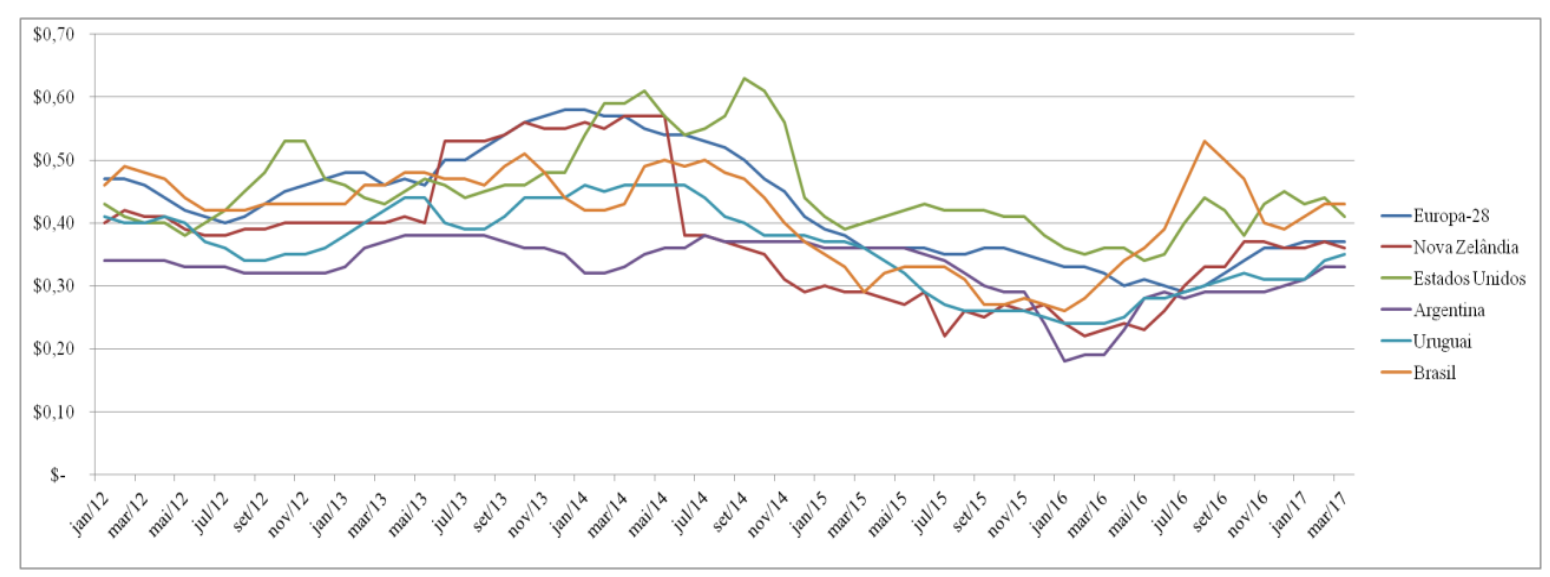

Fonte: Tabela elaborada por Milk Point com base nos dados de LTO nederland, Infortambo, CLAL, CEPEA/ESALQ. Disponível em: www.milkpoint.com.br Acesso em 23/05/2016

\section{GRÁFICO 03 - Importações e exportações de lácteos no Brasil em equivalente- leite (milhões de litros)}

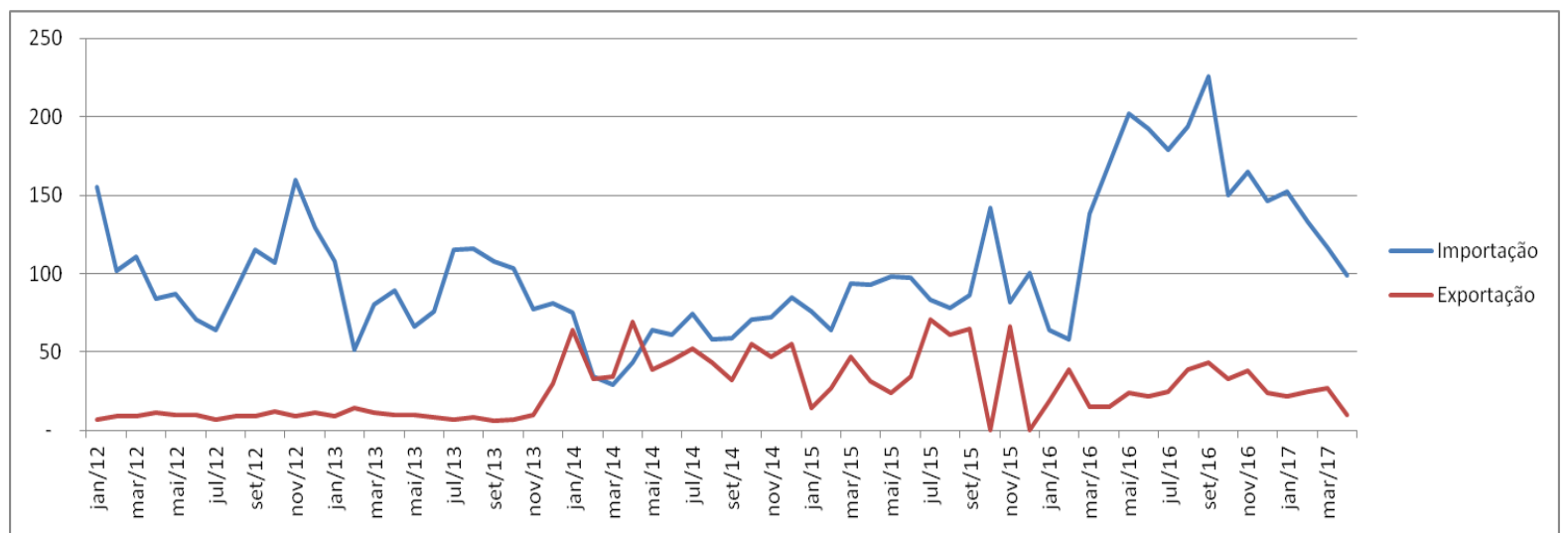

Fonte: Ministério do Desenvolvimento, Indústria e Comércio Exterior-MDIC, Milk Point. Disponível em www.milkpoint.com.br Acesso em 23/05/2016

Nota-se que as flutuações de preços no leilão GDT são acompanhadas, com certo atraso, pelos preços pagos aos produtores em países selecionados. Objetivando melhor compreensão, neste recorte temporal, o período que corresponde a janeiro de 2013 a janeiro de 2014, os preços do leilão GDT apresentaram consideráveis elevações. O mesmo ocorrera com os preços dos produtores de leite, mas o período de elevação foi de maio de 2013 a março de 2014, atentando ainda para o fato de que a queda nos preços dos produtores tem uma resposta mais imediata do que a queda dos preços no leilão GDT.

A relação existente entre as importações e as exportações de lácteos e as flutuações dos preços no leilão GDT também podem ser notadas ao analisar os gráficos, nada obstante, a tendência de aumento ou redução nas exportações e importações, deve-se a uma complexa relação entre preço da matéria-prima 
doméstica, câmbio, demanda interna e preços internacionais das commodities lácteas.

Vislumbra-se ainda, com base nos gráficos, que podem ocorrer diversas situações de correlação. De março a maio de 2014, as exportações superaram as importações no Brasil mesmo com os preços do leilão GDT em constante queda; já em setembro de 2015, as importações subiram substancialmente respondendo à queda de preços no GDT, ao mesmo tempo em que as exportações foram reduzidas significativamente.

Neste cenário, faz-se relevante compreender que empresas como Fonterra (Joint Venture com a Nestlé formando a Dairy Partners América - DPA) estão presentes no Brasil. Portanto, fazendo uso da produção nacional, para comercializar commodities lácteas para outros países e também utilizando métodos de triangulação para comercializar suas mercadorias oriundas da Nova Zelândia para países do Mercosul, passando pelo Brasil, ou quaisquer outros países que tenham métodos proteção contra importações predatórias mais flexíveis. Esses elementos podem desconfigurar a relação existente entre os preços do leilão GDT e as importações e ou exportações ${ }^{7}$.

Em meio a essa estrutura internacional consolidada ainda existem, na cadeia produtiva de lácteos do Brasil, os comerciantes sem fábrica (funcionando como trade company nacionais) que são fortemente especulativos em relação aos preços do leite e derivados, buscando sempre os menores preços, sejam estes na indústria interna ou na importação. Tais agentes condicionam fortemente a relação existente entre os preços internacionais e os preços internos, pois enaltecem 0 comportamento dos preços à medida que se colocam como intermediadores na comercialização de lácteos praticada entre indústria processadora de leite, de alimentos que demandam derivados de leite e o varejo (super e hipermercados). Dado este cenário, Gonçalves sugere que:

Mais ainda, porque os ajustes acabam se produzindo no campo, onde se localiza o elo tomador de preços. Isso porque a grande empresa da agroindústria de processamento enfrenta a solidificação de duas estruturas

\footnotetext{
7 Em entrevista concedida ao Jornal do Comércio (16/08/2017) segundo o secretário executivo do Sindicato da Indústria de Laticínios e Produtos Derivados (Sindilat), Darlan Palharini afirma que possivelmente o Uruguai por meio de incentivos esteja estimulando triangulação importando para o Brasil lácteos oriundos de outros países. Ainda nesta reportagem são exibidos dados que indicam tal informações. Segundo dados do Uruguai "o país produziu 1,7 bilhão de litros de leite em 2016 e consumiu 700 milhões de litros, o saldo, se convertido em pó, renderia 120 mil toneladas. Só o Brasil recebeu 100 mil toneladas de leite em pó e 18 mil toneladas em queijos do país vizinho, o que representa praticamente todo o volume restante".
} 
empresariais de mesma ou ainda maior magnitude de concentração do capital, que são os oligopsônios representados pelas "tradings company" atuantes no comércio exterior - que também atuam comprando diretamente dos agropecuaristas para produtos não processados - e pelas grandes redes de supermercados. Dado que ambos oligopsônios têm imenso poder de mercado e consequentemente de formar preços, na execução de sua governança sobre o processo, quando submetidos a pressões que comprometam suas margens, adotam estratégias de repassar o ajuste para os elos à montante das cadeias de produção (GONÇALVES, 2005, p. 13).

A inserção do mercado de lácteos no cenário internacional implica em colocar toda a cadeia produtiva nacional e suas respectivas mercadorias em um páreo com as maiores empresas de laticínios do mundo. Ao considerar todas as vantagens competitivas que estas empresas possuem, o reflexo nos preços dos produtores se torna apenas um, dentre vários elementos, que a cadeia produtiva do leite brasileira demonstra para competir com os produtos internacionais.

A indústria láctea promoveu alterações significativas em processos e produtos, tanto a montante quanto a jusante do processo, impulsionando outros agentes que fazem parte deste processo, a promoverem suas mudanças estruturais e organizacionais. De produtores de leite, passando pelos sistemas de transporte e armazenagem, linhas de produção e sistemas de comercialização, todos esses agentes sofreram mudanças para adaptarem-se às condições concorrenciais via preço e produto agora impostas por cotações internacionalmente determinadas. No entanto, devem-se considerar, as medidas protecionistas nacionais (tarifas alfandegárias, sobretaxas e subsídios) que protegem os produtos nacionais do comércio internacional. Observa-se na tabela sequente as tarifas aplicadas sobre os principais derivados lácteos.

QUADRO 01 - Tarifas de importação para produtos lácteos

\begin{tabular}{|l|c|}
\hline \multicolumn{1}{|c|}{ DESCRIÇÃO } & $\begin{array}{c}\text { TEC } \\
(\%)\end{array}$ \\
\hline $\begin{array}{l}\text { Leite e creme de leite (nata*), não concentrados nem } \\
\text { adicionados de açúcar ou de outros edulcorantes. }\end{array}$ & 14 \\
\hline Leite UHT (Ultra High Temperature) & 14 \\
\hline UHT (Ultra High Temperature) & 14 \\
\hline Outros & 12 \\
\hline $\begin{array}{l}\text { Leite e creme de leite (nata*), concentrados ou adicionados de } \\
\text { açúcar ou de outros edulcorantes. }\end{array}$ & 28 \\
\hline Em pó, Leite integral, Leite parcialmente desnatado & 28 \\
\hline Sem adição de açúcar ou de outros edulcorantes & 14 \\
\hline
\end{tabular}




\begin{tabular}{|l|c|}
\hline \multicolumn{1}{|c|}{ DESCRIÇÃO } & $\begin{array}{c}\text { TEC } \\
(\%)\end{array}$ \\
\hline Outros & 28 \\
\hline $\begin{array}{l}\text { Leitelho, leite e creme de leite (nata*) (coalhados, iogurte, quefir e } \\
\text { outros leites e cremes de leite (natas } \\
\text { acidificados. }\end{array}$ & 16 \\
\hline logurte & 16 \\
\hline Outros & 14 \\
\hline $\begin{array}{l}\text { Soro de leite, mesmo concentrado ou adicionado de açúcar ou } \\
\text { de outros edulcorantes. }\end{array}$ & 28 \\
\hline Manteiga e outras matérias gordas provenientes do leite; & 16 \\
\hline Queijos e requeijão. & \\
\hline Muçarela & 28 \\
\hline Outros & 16 \\
\hline $\begin{array}{l}\text { Com um teor de umidade igual ou superior a 36,0 \% e inferior a } \\
46,0 \%, \text { em peso (massa semidura) }\end{array}$ & 28 \\
\hline $\begin{array}{l}\text { Com um teor de umidade igual ou superior a 46,0 \% e inferior a } \\
55,0 \%, \text { em peso (massa macia) }\end{array}$ & 16 \\
\hline
\end{tabular}

Fonte: Ministério da Indústria, Comércio Exterior e Serviços (2017)

A tonelada de leite em pó no leilão GDT, em setembro de 2017, foi de U\$ 3.100,00, cerca de $R \$ 9.672$, considerando o câmbio em $R \$ 3,12$ em 18/19/2017, cotado pelo Banco Central do Brasil. Assim, cada quilograma de leite em pó negociado custa para o comprador Brasileiro cerca de $R \$ 9,67$ mais a alíquota de importação de $28 \%$ atingindo assim um preço de $R \$ 12,38$. Bem, para cada quilograma de leite em pó são necessários cerca de 9 litros de leite (considerando os sólidos totais - ST deste leite em torno de $12 \%)^{8}$.

Orientando-se pelo CEPEA - USP, o valor do litro de leite pago ao produtor em agosto, na média nacional, foi de $R \$ 1,26$ bruto - considerando frete e Funrural. Bem, com leite brasileiro é possível obter um quilograma de leite em pó a custo de $R \$ 11,34$ cerca de $R \$ 1,04$ de diferença com o leite importado, porém, aqui não são considerados os custos de produção, nem o fato de que com um leite com menor teor de sólidos são necessários 10 litros para fabricar um quilograma de leite em pó. Assim, pode-se afirmar que, mesmo com alíquotas de $28 \%$ às margens da indústria de laticínios são reduzidas, tendo assim, em alguns períodos do ano, dificuldades para competir com os derivados lácteos que são importados.

\footnotetext{
${ }^{8}$ Segundo a Embrapa o termo sólido total - ST engloba todos os componentes do leite exceto a água. Basicamente o leite é composto por cerca de $87 \%$ de água e os outros 12 a $13 \%$ são os ST. Estes por sua vez são constituídos de lipídios (gordura), carboidratos, proteínas, sais minerais e vitaminas. Informações disponíveis em: http://www.agencia.cnptia.embrapa.br/Agencia8/AG01/arvore/AG01 128 21720039243.html
} 
De forma simplificada, é possível concluir que flutuações nos preços do leite pago ao produtor de leite e ao consumidor dos derivados lácteos estão relacionadas a: Primeiro, para o produtor: pelas condições de produção - clima que por sua vez interferem nas pastagens, na produção de insumos, a produtividade da terra e dos animais entre outros elementos ligados a natureza. Segundo, para o consumidor: condições de oferta e procura, livre concorrência, avanço mais significativo das tecnologias (processos e produtos) o que leva a uma mais veloz tendência geral da queda da taxa de lucros fazendo com que derivados lácteos estejam consolidados como produtos básicos de forma mais rápida.

É bom lembrar que essa interpretação vai além e deve considerar que as condições dos novos sistemas de comercialização de leite são fundamentadas nas estruturas desiguais estabelecidas historicamente pelo avanço do modo de produção do capital e na recente manifestação do capitalismo financeiro nos países em desenvolvimento, na globalização dos mercados, traduzidas em desnacionalização da indústria e varejo nacional. São aliadas ainda a novas e desfavoráveis condições e termos de importação/exportação e na consolidação de cadeias produtivas compostas por empresas oligopolizados que estão impondo nacionalmente as condições de produção/industrialização de países de primeiro mundo pioneiros na atividade leiteira.

\footnotetext{
Essa centralização do capital resultou em empresas que extravasaram o sue estado de origem - as multinacionais - e que, sob a hegemonia do capital financeiro, se encarregaram de estabelecer uma nova divisão social do trabalho entre as nações do "centro" e as da "periferia". Não nos interessa aqui perguntar como e por que foi assim. Mas, assim como a batida do coração repercute na artéria mais distante, a "periferia" tem de "pulsar" no ritmo dado pelas necessidades da acumulação do capital do "centro". E, à medida que se estreitou a solidariedade das "nações periféricas" com o capitalismo internacional, via multinacionais, as economias periféricas se tornaram necessariamente, reflexas. (GRAZIANO DA SILVA, 1982, p.20)
}

Isso coloca toda a cadeia produtiva que ainda é nacional em competição no livre mercado com os maiores e mais avançados sistemas produtivos que existem. Para o produtor de leite especificamente, sua atividade é condicionada pela capacidade de produzir com a qualidade desejada a custos extremamente reduzidos que atendam às demandas das indústrias que, por sua vez, exploram o mercado consumidor local. Neste sentido, dadas as condições expostas até então, a produção nacional de leite é favorecida quando se torna conveniente por questões 
logísticas - embora, constantemente, tal produção seja relegada a segundo plano quando o mercado internacional oferta leite e derivados com valores reduzidos.

\begin{abstract}
A variação do preço do leite pago ao produtor ocorre no mundo todo e está mais relacionada à oferta e à demanda do produto no mercado internacional do que ao custo de produção. Nos países exportadores e importadores, observa-se a oscilação do preço do leite ao longo do ano. Por exemplo, nos Estados Unidos, que participam do mercado internacional como exportadores e importadores [...] O preço do leite ao produtor é um reflexo do comportamento registrado no mercado mundial (ZOCCAL, 2016).
\end{abstract}

Depreende-se daí que, para o produtor de leite do Brasil, o preço pago para o leite produzido não está ligado às condições naturais de seu território, mas às condições estruturais com que o mercado está organizado, permitindo que prevaleçam as condições de produção de países de primeiro mundo sobre a produção nacional. Equivale dizer que são as condições naturais dos países de primeiro mundo que condicionam as flutuações nos preços do leite produzido no mundo todo, restando a produção nacional adaptar-se às condições que o mercado impõe, sem considerar as condições naturais de cada Região do Brasil.

Apreende-se que, muito aquém das intempéries nacionais, as flutuações nos preços das commodities lácteas são resultados da soma de fatores internos de diversos países tidos como maiores produtores consumidores de leite inseridos em uma economia globalizada. [...] "o avanço da financeirização da agricultura condicionou essa à sua dinâmica, relegando os fatores propriamente agrícolas como o volume das safras, a dinâmica climática e o consumo de alimentos a segundo plano". (MEDEIROS, 2015, p. 14)

Sob os mesmos aspectos, na outra ponta da cadeia produtiva, estão os consumidores que, para o caso do Brasil, não são favorecidos pela livre concorrência. À medida que grandes oligopólios industriais e do varejo são consolidados, todos os benefícios são traduzidos em redução de custos, enquanto que os processos otimizados por toda a cadeia produtiva não refletem sob o preço da mercadoria e são absorvidos pela capacidade de grandes empresas (estruturadas pelo capital financeiro) de dominarem a cadeia produtiva e tomarem para si os benefícios (maiores receitas) do progresso técnico e da condição de oligopólio/oligopsônio.

Noutros termos, a reprodução ampliada do capital inseriu de forma plena a agricultura na lógica da financeirização da riqueza num universo 
globalizado. Nesse sentido, os movimentos setoriais de desenvolvimento da agricultura se dão nesse contexto e com base nessa lógica é que devem ser pensadas as estratégias para 0 novo ciclo de expansão setorial (GONÇALVES, 2005, p.08).

Afirma-se, a partir daí, que a elevação no preço dos alimentos, observado também para os derivados lácteos, não se deve ao aumento do consumo mundial, e as flutuações destes preços não se devem à oferta e à demanda, ou ainda somente pelas condições de produção. Os preços são controlados pelo mercado financeiro, como anuncia Medeiros (2015, p.24): "Os mercados financeiros tornaram-se os principais agentes das supersafras ou da escassez de alimentos, mais do que 0 clima ou do que o aumento da demanda por alimentos". Ocorre que as vendas antecipadas nos mercados futuros estão condicionando a produção muito antes que ela ocorra. A alta especulação financeira sobre as commodities agrícolas é o principal fator de elevação dos preços internacionais dos alimentos conforme Medeiros (2015).

\section{Considerações finais}

As informações e dados apresentados fundamentaram analises que apontam para o fato de que grandes empresas multinacionais oligopolizadas presentes no Brasil mantem mecanismos de controle de preço, des/abastecimento, redução de capacidade ociosa (para unidades industriais) em níveis regionais, por meio de um amplo processo especulativo promovido em nível internacional, onde grandes volumes de derivados lácteos são comercializados, importados ou exportados de vários países do mundo, inclusive do Brasil. Sob tais condições os preços praticados internamente são controlados de forma direta pelas empresas, e estas por sua vez convertem e manejam suas polícias de pagamento ao produtor, e preços ao consumidor de forma que garantirem seus lucros mesmo frente as sazonalidades produtivas ou de demanda. Da mesma forma garantem sua receita mesmo sob distintas condições com as quais as questões estruturais e conjunturais da economia configuram o mercado.

As conclusões obtivas permitem revelar elementos que justificam a complexidade com que se constitui a cadeia produtiva do leite no que tange a formação dos preços praticados pela indústria, atacado e varejo, levando a perceber que sob determinadas condições, o livre mercado, a concorrência, as leis de oferta 
de demanda, bem como as vantagens comparativas, fatores naturais edafoclimáticos para a produção, ou quais quer outra, estrutura, de mercado, humana, natural ou legislativa, podem não explicar com precisão o comportamento dos preços de determinado segmento produtivo. $O$ tamanho da estrutura industrial, sua abrangência espacial e internamente no complexo produtivo, bem como o volume de recursos disponíveis, dá a certas empresas vantagens de monopólio, controlando direta e indiretamente a produção e os agentes a montante e a jusante do processo, bem como manipulando e ditando tendências e padrões de consumo para grandes mercados consumidores pelo mundo.

Isto posto, é passível afirmar que agentes da cadeia produtiva com menor capacidade atuação estratégica sob os demais, são impelidos a organizar sua atividade mediante a condições determinadas pelas grandes empresas de laticínios, assim como transportadores e pequenos varejos para grandes distribuidores ou consumidores para grandes redes varejistas. Outro principal aspecto desta condição se traduz nos altos índices de capacidade de transferência da receita gerada pelo processo entre os elos da cadeia, a redução da receita para alguns elos, e o aumento da receita para outros elos se dá por meio deste processo e não somente pelo nível de eficiência produtiva. Apesar disso ainda se sustenta a ideia de que o aumento do lucro está somente ligado a eficiência de cada agente, induzindo produção em escalas e ou a exclusão da atividade, fazendo como que os espaços produtivos sejam transformados, reconfigurando a produção e concentrando produção e capital.

Assim, a ótica geográfica, se valendo de analises economicistas, a construção, desenvolvimento, reprodução, sustentabilidade, transformação ou destruição das atividades produtivas em seus respectivos espaços - regiões, estão profundamente relacionadas a produção material e a reprodução do capital, que permitiu a formação de grandes empresas globais e estas sob esta condição, criaram novos mecanismos, mais eficientes que a dinâmica natural de auto ajuste do livre mercado. Significa dizer, que complexos produtivos onde se fazem presentes, grandes empresas monopolizadas exigem, para seu entendimento uma quebra dos paradigmas metodológicos para análise e entendimento de sua atuação, mas que não desconsidere a reprodução e acumulação de capital como objetivo principal destes empreendimentos.

\section{REFERÊNCIAS}


BALESTRO Moisés Villamil; LOURENÇO Luiz Carlos de Brito. Notas para uma análise da financeirização do agronegócio Além da volatilidade dos preços das commodities. IN O mundo rural no Brasil do século 21: a formação de um novo padrão agrário e agrícola. Antônio Márcio Buainain, Eliseu Alves, José Maria da Silveira, Zander Navarro, editores técnicos. - Brasília, DF: Embrapa, 2014.

CEPEA - Centro de Estudos Avançados em Economia Aplicada. ESALQ/USP. Boletins do Leite. Várias edições (2014/15). Disponível em: http://cepea.esalq.usp.br/leite/

CPI DO LEITE. Relatório final proposta de fiscalização e controle no 63/2001. deputado /Moacir Micheletti - relator. Acesso em 17/01/2019. Disponível em:

/http://www.camara.gov.br/proposicoesWeb/prop mostrarintegra;jsessionid=ACFB8AE65A4 8C8A329B2F23B253DB3C5.proposicoesWebExterno2?codteor $=161203 \&$ filename=Tramitac ao-PFC+63/2001

FAEP. Potencial de escoamento da produção agropecuária paranaense. Publicado em Destaques, pecuária do leite em 10/07/2017. Disponível em:

http://www.sistemafaep.org.br/servico/potencial-de-escoamento-da-producao-agropecuariaparanaense

FILHO, Rafael. Como funcionam os leilões de lácteos da plataforma Global Dairy trade (GDT)? Reportagem exibida no canal eletrônico Scot Consultoria. Quarta-feira, 4 de dezembro de 2013. Disponível em: www.scotconsultoria.com.br.

GRAZIANO da SILVA, JOSÉ. Modernização dolorosa - estrutura agrária, fronteira agrícola e trabalhadores rurais no Brasil. Zahar Editores, Rio de Janeiro 1982.

GONÇALVES. José Sidney. Agricultura sob a égide do capital financeiro: passo rumo ao aprofundamento do desenvolvimento dos agronegócios. In: Informações econômicas, São Paulo. v. 35. n. 4, 2005.

MEDEIROS, Marlon. Estado, capital financeiro e agricultura no Brasil atual. XI Encontro nacional da AMPEGE - A diversidade da geografia brasileira: escalas e dimensões da análise e da ação. Anais do evento. 9 a 12 de outubro de 2015.

ZOCCAL Rosângela. Conjuntura atual da produção de leite no mundo. Reportagem exibida em: 13 de dezembro de 2016. Acessado em 12/09/17. Disponível em:

http://www.baldebranco.com.br/conjuntura-atual-da-producao-de-leite-no-mundo/

\section{NOTAS DE AUTOR}

\section{CONTRIBUIÇÃO DE AUTORIA}

Pablo Jonas Camilo- Concepção. Coleta de dados, Análise de dados, Elaboração do manuscrito, revisão e aprovação da versão final do trabalho

\section{FINANCIAMENTO}

Coordenação de Aperfeiçoamento de Pessoal de Nível Superior - CAPES

CONSENTIMENTO DE USO DE IMAGEM

Não se aplica.

\section{APROVAÇÃO DE COMITÊ DE ÉTICA EM PESQUISA}

Não se aplica. 


\section{LICENÇA DE USO}

Este artigo está licenciado sob a Licença Creative Commons CC-BY. Com essa licença você pode compartilhar, adaptar, criar para qualquer fim, desde que atribua a autoria da obra.

\section{HISTÓRICO}

Recebido em: 30-01-2019

Aprovado em: 03-03-2019 